\title{
Lifetime risk of pregnancy-related death among Zambian women: district-level estimates from the 2010 census
}

\author{
Richard Banda ${ }^{1,2}$ - Ingvild Fossgard Sandøy ${ }^{3}$. \\ Knut Fylkesnes $^{3} \cdot$ Fanny Janssen $^{4,5}$
}

Published online: 2 June 2016

(C) The Author(s) 2016. This article is published with open access at Springerlink.com

\begin{abstract}
The aim of this study was to examine district differentials in the lifetime risk of pregnancy-related death among females aged 15-49 in Zambia. We used data on household deaths collected in the 2010 census to estimate the lifetime risk of pregnancy-related death among females in Zambia. Using all-cause age-specific death rates, we generated female life tables for 74 districts and estimated personyears of exposure to all-cause mortality at each age. We then applied age-specific pregnancy-related mortality rates to the person-years of exposure to obtain estimates of adult lifetime risk that took account of competing causes of death. We used the ArcGIS software to analyse clustering and the spatial distribution of risk. A female aged 15 in Zambia had a $3.7 \%$ chance of dying a pregnancy-related death before the age of 50. At district level, the lifetime risk ranged from 1.7 to $7.7 \%$. The Global Moran's I was 0.452 ( $z$-score $5.8, p$ value $<0.01$ ), indicating clustering of districts with similar risk levels of pregnancy-related mortality. Clustering of highrisk districts was found in Western province while clustering of low risk districts was found in Lusaka and Muchinga provinces. The level of adult lifetime risk was more positively associated with pregnancy-related mortality than with fertility. Females in Zambia have a high lifetime risk of pregnancy-related death overall but this risk varies greatly across the different districts of the country. The observed diversity is larger than when merely studying differences between provinces and is
\end{abstract}

Richard Banda

richard.banda@student.uib.no; richardbanda@gmail.com

1 Central Statistical Office, Lusaka, Zambia

2 Centre for International Health, University of Bergen, Bergen, Norway

3 Centre for Intervention Science in Maternal and Child Health (CISMAC), Centre for International Health, University of Bergen, Bergen, Norway

4 Population Research Centre, University of Groningen, Groningen, The Netherlands

5 Netherlands Interdisciplinary Demographic Institute, The Hague, The Netherlands 
only weakly linked to differences in fertility levels. The identification of districts with varying levels of risk should enable evidence-based and focused delivery of maternal health services in districts where risk of death from maternal causes is greatest.

Keywords Pregnancy-related death - Lifetime risk - Census - Zambia - Maternal mortality

\section{Background}

An estimated 289,000 women globally died of maternal causes in 2013, with $62 \%$ of these deaths occurring in sub-Saharan Africa (World Health Organisation et al. 2014). Studies show that the main direct obstetric causes of maternal deaths are haemorrhage, hypertensive disorders of pregnancy, sepsis and complications of abortion (Ronsmans et al. 2006; Say et al. 2014). Although many women die annually from maternal causes, such deaths are preventable with known interventions (Campbell and Graham 2006; Ronsmans et al. 2006). To reduce maternal mortality, interventions must be focused in areas where women face the greatest risk (Ronsmans et al. 2006).

The level of maternal mortality in a population is considered to be a result of a combination of the risk of death during pregnancy or childbirth and the level of fertility (World Health Organisation et al. 2014). The adult lifetime risk (ALTR) of maternal mortality is therefore an important indicator of the reproductive health status of the population as it measures the cumulative loss of adult female life due to maternal causes (Wilmoth 2009). While the maternal mortality ratio (MMRatio) is an important indicator of the current magnitude of mortality due to maternal causes, the ALTR gives an indication of the number of deaths that could potentially be averted (Graham et al. 2007).

Several methods are used to estimate the ALTR, mostly determined by the type and source of available data. The ideal method requires the use of age-specific data on maternal deaths and the population at risk of such deaths (Wilmoth 2009). Lack of age-specific data prevents the appropriate estimation of the ALTR for subnational levels. Therefore more indirect methods using the maternal mortality rate (MMR) and the MMRatio are often used (Graham et al. 2007; Wilmoth 2009; World Health Organisation et al. 2014). Since actual maternal deaths are challenging to measure, especially in settings with incomplete vital registration systems, pregnancy-related deaths are often used as a proxy for maternal deaths in the estimation of ALTR.

The ALTR varies greatly across countries. In 2010, the United Nations (UN) estimated that globally, 1 in every 108 women died of maternal causes during her reproductive life course, and the risk was much higher in sub-Saharan Africa where 1 in every 37 women died from such a cause (World Health Organisation et al. 2012). Within sub-Saharan Africa, the ALTR ranged from 1 in every 15 women in the Republic of Chad to 1 in every 1000 women in Mauritius (World Health Organisation et al. 2012). The UN estimate for Zambia for the year 2010 was also 
substantial: one woman in every 37 women, or $2.7 \%$, died of maternal causes during her reproductive life course (World Health Organisation et al. 2012).

Just as the ALTR varies across countries, in-country variations also exist, reflecting differences in the determinants of risks faced by women during pregnancy and childbirth in the different regions. Studies examining geographical differences in ALTR, beyond the urban-rural differences, are rare, however. For Zambia, only two studies so far, conducted in two different provinces in the late 1990s, provide an indication of subnational estimates of the ALTR. Both studies used the sisterhood method and therefore identified pregnancy-related deaths of females of reproductive age. The study conducted in Kalabo in the Western province estimated the ALTR to be $8.5 \%$ (Vork et al. 1997), while the study covering two districts in Northern province (Kasama and Kaputa districts) estimated ALTRs of 5.4 and $11.0 \%$, respectively (Le Bacq and Rietsema 1997). None of the studies took competing causes of adult female deaths into account in generating their estimates of ALTR although competing causes can be particularly important in settings where adult female mortality from non-maternal causes is also high, as was the case in Zambia at the time of the two studies.

In October 2010, Zambia conducted a national population census in which information on pregnancy-related deaths was collected (Central Statistical Office 2012a). This was the first time that the country had included such information in a census and it followed the recommendation by the UN to consider maternal mortality a core topic in the 2010 round of national population censuses (United Nations Statistics Division 2008). This provided a unique opportunity to study pregnancy-related mortality at a subnational level, including the estimation of the ALTR using age-specific data and taking into account other causes of death among reproductive-age women. No previous studies in Zambia have done this.

In this paper, alongside our examination of the district differentials in lifetime risk of pregnancy-related death among females aged 15 in Zambia, we also assess the associations of the prevailing level of lifetime risk with both fertility and pregnancy-related mortality.

\section{Methods}

\section{Setting}

For our study on district differentials in lifetime risk of pregnancy-related deaths among women in Zambia, we used the Zambia 2010 census. The Zambia 2010 census was conducted in October 2010 using the traditional approach of door-todoor canvassing of all households in Zambia by about 33,000 enumerators, supervisors and other census field staff (Central Statistical Office 2012a). At the time of the census, the country had 74 districts and nine provinces. A tenth province was created soon after the census, and geographic data was re-coded to enable the generation of estimates for ten provinces namely; Central, Copperbelt, Eastern, Luapula, Lusaka, Muchinga, Northern, North Western, Southern and Western provinces (Central Statistical Office 2012a). This study made use of data for the 74 
districts and 10 provinces. See the "Appendix" for a map of Zambia showing both provinces and districts.

\section{Data on pregnancy-related deaths}

The World Health Organization (WHO) identifies a pregnancy-related death as a "death of a woman while pregnant or within 42 days of termination of pregnancy, irrespective of the cause of death" (World Health Organization 2009). The Zambia 2010 census collected information on deaths during the period 12 months prior to the census and for households reporting deaths of females aged 12-49, inquiry was made to ascertain the death relative to pregnancy; "Did the death occur while pregnant?" If the answer was "no" to this question, the census household respondent was asked: "Did the death occur during childbirth?" and if the answer was "no" to this too, a third question was posed: "Did the death occur during the 6 week period following the end of pregnancy, irrespective of the way the pregnancy ended?" (Central Statistical Office 2012a). For our analysis, we defined pregnancy-related deaths as captured in the census i.e. any reported deaths of women during pregnancy, childbirth or within the six-week period after termination of pregnancy. Due to the small number of pregnancy-related deaths in the age group 12-14, our analysis focused on reported deaths of women aged 15-49. Since methods for evaluating the completeness of pregnancy-related deaths recorded in a census are not currently available (Hill et al. 2011; Hill and Stanton 2011), we made no adjustment to the pregnancy-related deaths. However, we assessed the age pattern and the proportional contribution of pregnancy-related deaths to the total number of deaths of reproductive age women as a check for plausibility (see also Banda et al. 2015).

We evaluated the completeness of all deaths reported by households in the census using an established method, the Brass Growth Balance method (United Nations 1983). Although the method assumes a stable and closed population, its application provided plausible estimates of adjusted mortality rates, which proved to be more realistic than the crude estimates (Banda et al. 2015). It was also convenient since it does not require the use of two censuses, as is the case for the General Growth Balance method.

\section{Data on fertility}

For us to assess the association between lifetime risk of pregnancy-related mortality and fertility, we also used census information on live births to women aged 15-49 in the 12 months preceding the census and children ever born (CEB) to women aged 15 years and older. Since live births are usually underreported in censuses, we used the Brass PF Ratio method (United Nations 1983) to evaluate completeness of reported live births, and to adjust the crude age-specific fertility rates (ASFRs). We used the average of the PF ratios for age groups 20-24, 25-29 and 30-34 in determining the adjustment factor for the reported number of live births. In order to compute appropriate ASFRs corrected for age misreporting by women reporting births in the census, we evaluated the census age distributions using the age-sex 
accuracy index (ASAI) (Shryock and Siegel 2004), and adjusted the age distribution for age heaping/digit preference using the Arriaga Technique (U.S. Census Bureau 1994), a mild smoothing method that maintains the population totals. The adjusted ASFRs were used in estimating the adjusted total fertility rate (TFR) and the adjusted total number of live births, used as denominator in the estimation of the pregnancy-related mortality ratio (PRMRatio).

\section{Estimation of adult lifetime risk of pregnancy-related death (ALTR)}

The adult lifetime risk of a maternal death is defined as the probability that a female survivor from birth to age 15, exposed to the observed age-specific maternal mortality rates during her reproductive life course, will die from maternal causes before age 50, taking account of competing causes of death (Wilmoth 2009). We applied this definition in our analysis of the risk of pregnancy-related death by replacing "maternal" in the definition with "pregnancy-related". We used agespecific death rates to generate period life tables for each of the 74 districts. Using population numbers and pregnancy-related deaths, we estimated age-specific pregnancy-related mortality rates (PRMRs) for each 5-year age group between age 15 and 50. From the period life tables, we estimated the number of person-years lived by a female aged 15 at each age, exposed to all-cause mortality, during her reproductive life course. We then estimated the ALTR by applying the age-specific PRMRs to the exposure (person-years) to all-cause mortality at each age, summed up over the entire reproductive age group, 15-49. In so doing, the estimate of ALTR takes into account competing causes of adult female deaths (Wilmoth 2009). We assumed that age-specific fertility and mortality rates prevailing at the time of the census would remain constant throughout the female reproductive life course.

\section{Analysis}

We mapped the spatial distribution of ALTR at district level using ArcGIS software version 10.2 (Environmental Systems Research Institute 2013) and tested for clustering using the spatial statistics tool, Global Moran's I. The Global Moran's I measures the spatial distribution of feature locations (in this case, districts represented as polygons with $\mathrm{x}-\mathrm{y}$ coordinates) and associated attributes (the ALTR) by evaluating whether the pattern expressed is clustered, dispersed, or random (Environmental Systems Research Institute 2013). The Global Moran's I tool computes an index and expected value using information about the feature locations and associated attributes. Index values fall between -1.0 and +1.0 ; negative values indicate dispersion, positive values indicate clustering and 0 indicates random spread. The computed index and expected values are then compared, and a $z$-score for the difference is computed, together with a $p$-value (indicating whether the difference of the two is statistically significant). The null hypothesis for this test is that the attribute (ALTR) is randomly distributed across feature locations (districts), and the value of the $p$-value is used to reject or accept the null hypothesis. We did similar analysis of clustering for the total fertility rate (TFR), proportion of female 


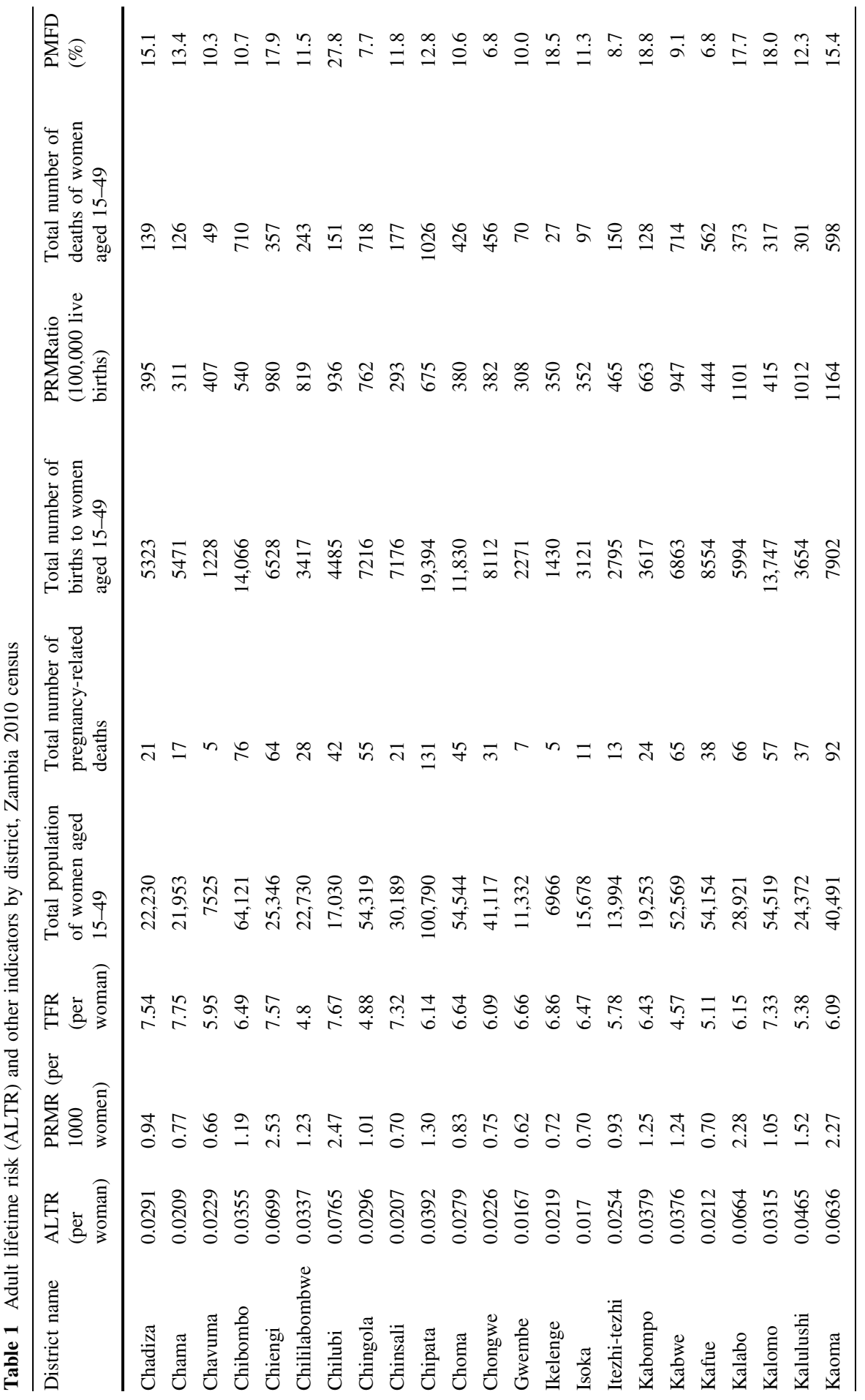




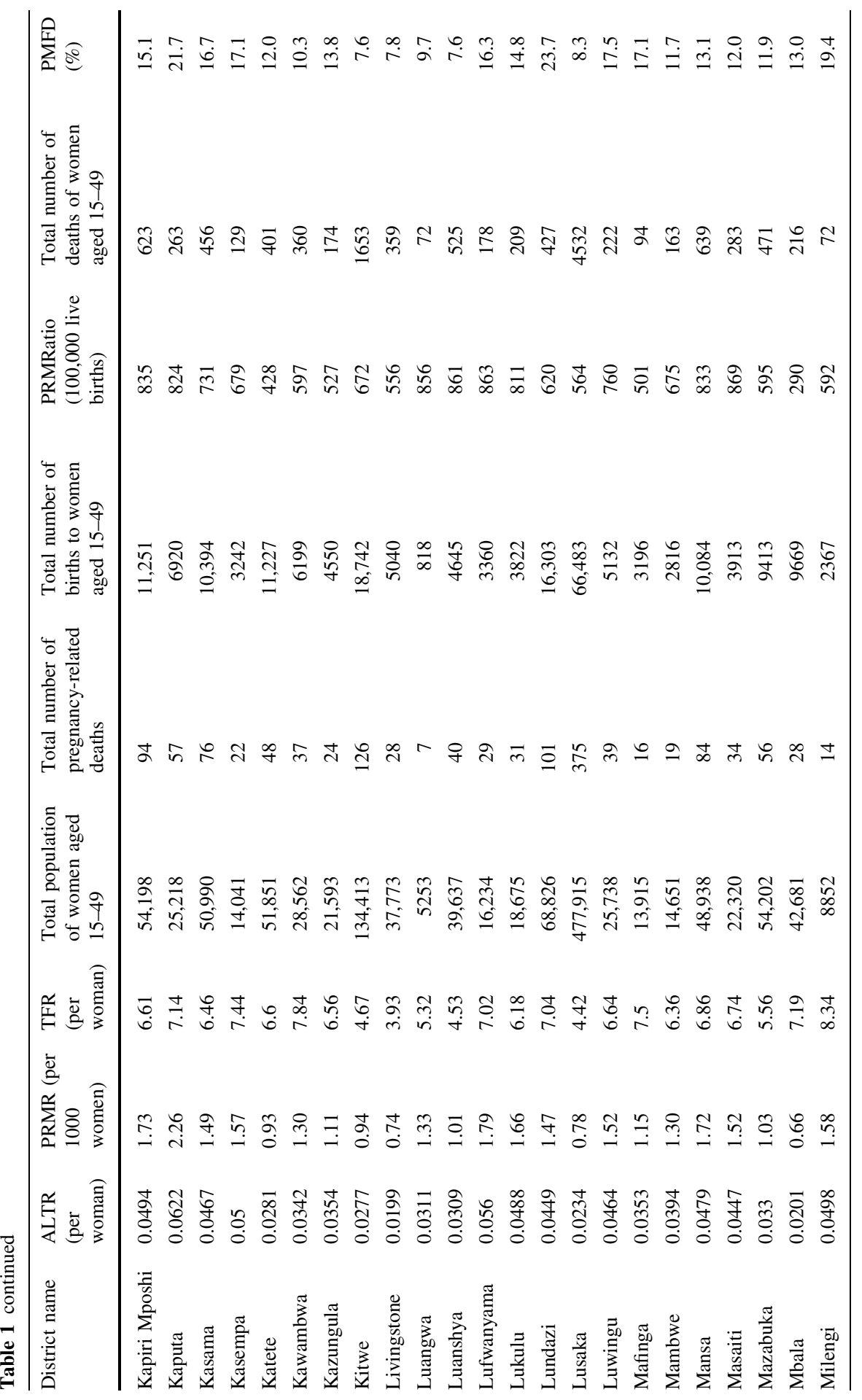




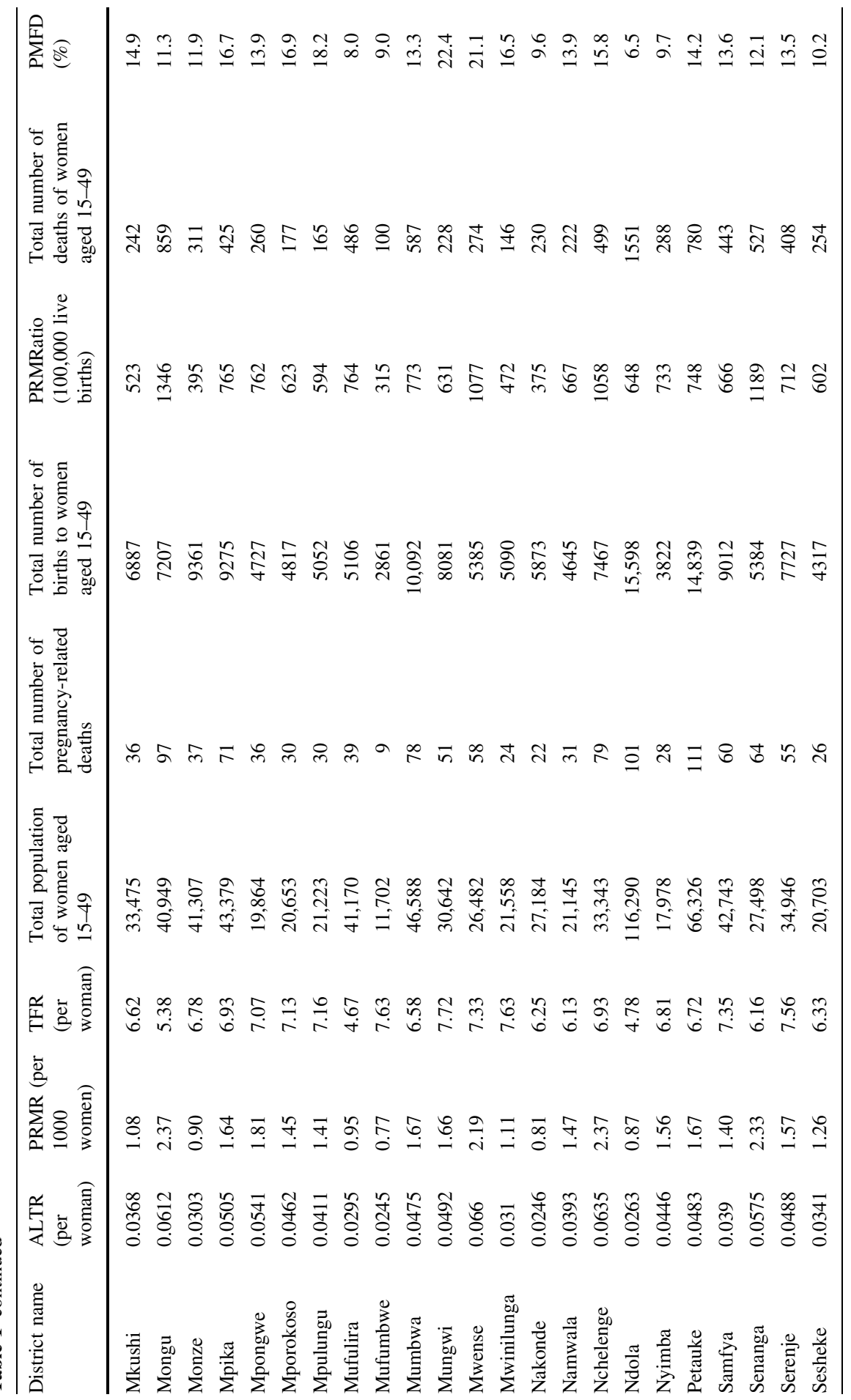




\begin{tabular}{|c|c|}
\hline 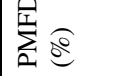 & 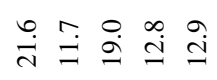 \\
\hline 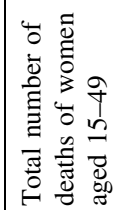 & 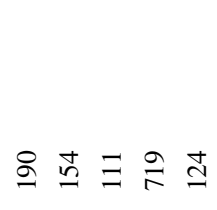 \\
\hline 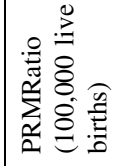 & 合守字学志 \\
\hline 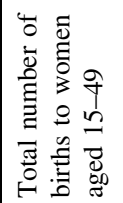 & 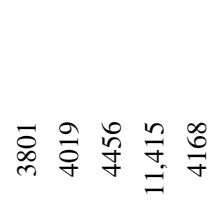 \\
\hline 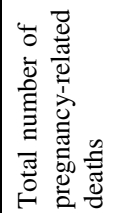 & $\exists \stackrel{\sim}{\sim} \sigma \mathscr{0}$ \\
\hline 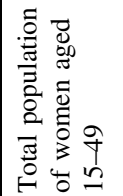 & 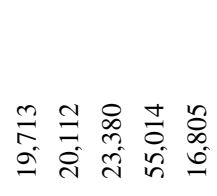 \\
\hline 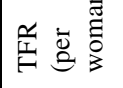 & 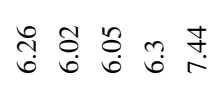 \\
\hline 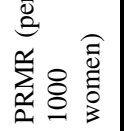 & 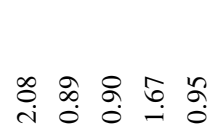 \\
\hline 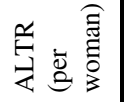 & 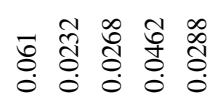 \\
\hline 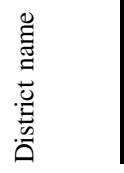 & 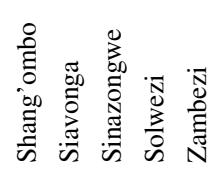 \\
\hline
\end{tabular}


deaths that are pregnancy-related (PMFD), PRMR, Births, Deaths and PRMRatio as a check against the main results.

We evaluated the associations between ALTR and two other indicators associated with risk of pregnancy-related deaths, TFR and PMFD, using scatter plots fitted with simple linear regression lines. For the purposes of illustrating the results, we used three districts, Ikelenge district in North Western province, Mongu district in Western province and Lusaka district, the capital of Zambia. Ikelenge was the smallest district in the country at the time of the census. It is a rural district, located at the border between Zambia and Angola to the west, and the Democratic Republic of the Congo to the north, and had a total population of 32,919 (Central Statistical Office 2013). Mongu is the capital of Western province and had a total population of 179,585, one third of which resided in urban areas (Central Statistical Office 2012a). Lusaka is located approximately in the centre of the country, is completely urban and had a total population of 1747,152 , with a population density of 4853 persons per square kilometre (Central Statistical Office 2012a).

\section{Ethical approval}

Our study used information from the 2010 census descriptive tabulations reports published by the Central Statistical Office (CSO) based on the full count of the country (Central Statistical Office 2012b). Use of such aggregated population data summaries, containing no personal identifiers, does not require ethical approval.

\section{Results}

A female aged 15 in Zambia at the time of the census in October 2010 had a $3.7 \%$ ( 1 in 27) chance of dying a pregnancy-related death before the age of 50, taking into account other causes of death among women of reproductive age. At district level, the ALTR ranged from $1.7 \%$ in Gwembe district to $7.7 \%$ in Chilubi district (Table 1). Half of the ten districts with the highest ALTR belonged to one province, Western province, while $40 \%$ of the 10 districts with the lowest ALTR also belonged to one province, Muchinga province. Among the 10 low-risk districts, the ALTR ranged from $1.7 \%$ ( 1 in 60 ) to $2.3 \%$ ( 1 in 44 ), while among the 10 high-risk districts, the ALTR ranged from $5.8 \%$ ( 1 in 17) to $7.7 \%$ (1 in 13).

Results of the Global Moran's I spatial autocorrelation analysis are summarised in Table 2, and based on the results, the null hypothesis that the ALTR was randomly distributed across the 74 districts must be rejected. The z-score of 5.81 was high enough to indicate that there was clustering of districts with similar levels of ALTR and this was statistically significant at $1 \%$ level of significance.

The clustering of districts is also evident in Fig. 1, which shows the district-level map of Zambia. The highest concentration of districts with very high ALTR was in Western province, where five out of a total of seven districts had an ALTR of $5.8 \%$ (1 in 17) or more. The concentration of low-risk districts was highest in Lusaka 
Table 2 Summary of Global Moran's I analysis of spatial clustering of various variables, Zambia 2010 census

\begin{tabular}{ccccccccc}
\hline & $\begin{array}{l}\text { Pregnancy- } \\
\text { related } \\
\text { deaths }\end{array}$ & Births & $\begin{array}{l}\text { Deaths } \\
\text { of } \\
\text { women } \\
\text { aged } \\
15-49\end{array}$ & PMFD & $\begin{array}{l}\text { Total } \\
\text { fertility } \\
\text { rate }\end{array}$ & PRMRatio & PRMR & $\begin{array}{l}\text { Adult } \\
\text { lifetime } \\
\text { risk }\end{array}$ \\
\hline $\begin{array}{c}\text { Moran's } \\
\text { index }\end{array}$ & 0.0443 & 0.0597 & 0.1011 & 0.2364 & 0.4092 & 0.4996 & 0.4967 & 0.4521 \\
$\begin{array}{c}\text { Expected } \\
\text { index }\end{array}$ & -0.0137 & -0.0137 & -0.0137 & -0.0137 & -0.0137 & -0.0137 & -0.0137 & -0.0137 \\
$\begin{array}{c}\text { Variance } \\
\text { z-score }\end{array}$ & 0.0041 & 0.0029 & 0.0031 & 0.0064 & 0.0064 & 0.0064 & 0.0064 & 0.0064 \\
p-value & 0.9106 & 1.3570 & 2.0526 & 3.1354 & 5.2855 & 6.4103 & 6.3652 & 5.8060 \\
\hline
\end{tabular}

$p$-value $<0.05$ indicates significant clustering of districts associated with similar levels of the variable of interest

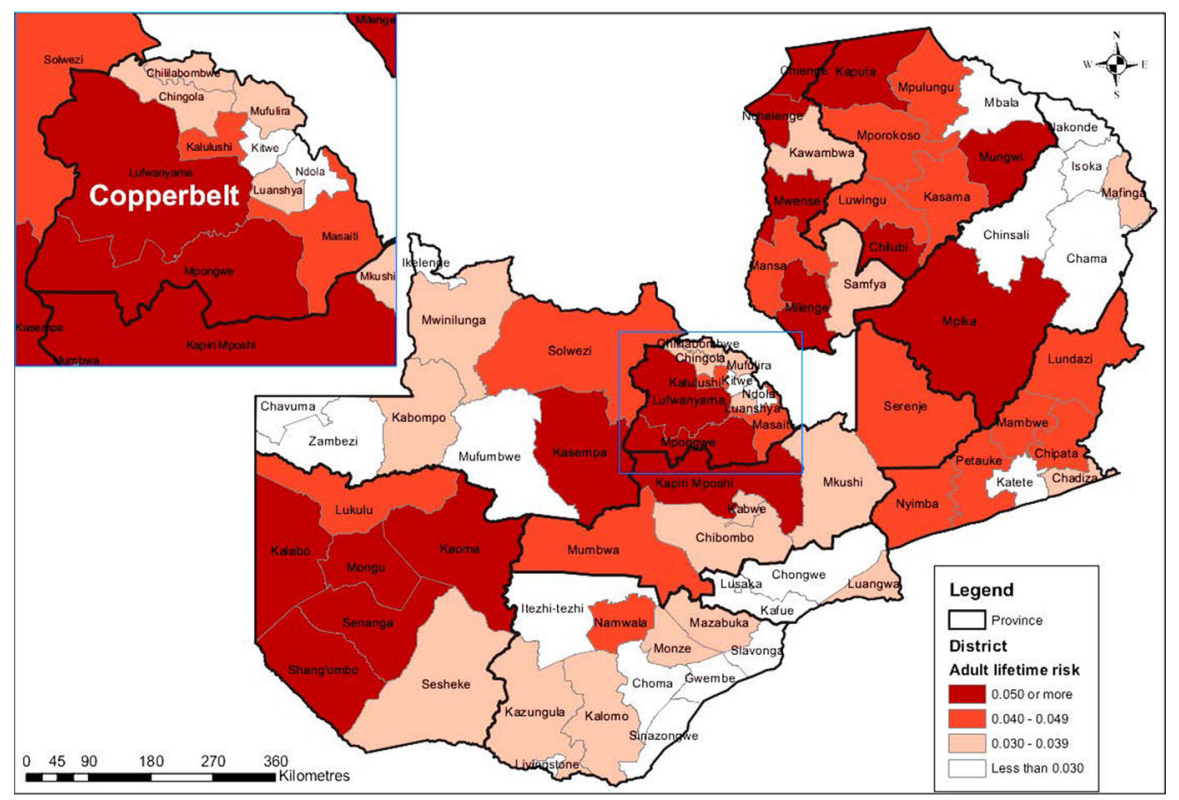

Fig. 1 District-level adult lifetime risk (ALTR) of pregnancy-related death per woman, Zambia 2010 census

province where three out of four districts had an ALTR of $2.3 \%$ (1 in 43) or less. In Lusaka province also, the PMFD was less than $10 \%$ in all the four districts.

Figures 2 and 3 show the association between the adult lifetime risk of pregnancy-related death for a female aged 15 in a district and the prevailing level of TFR and PMFD. Using the three districts (highlighted in the figures), results show that the overall association between the TFR and ALTR was positive, but there was 


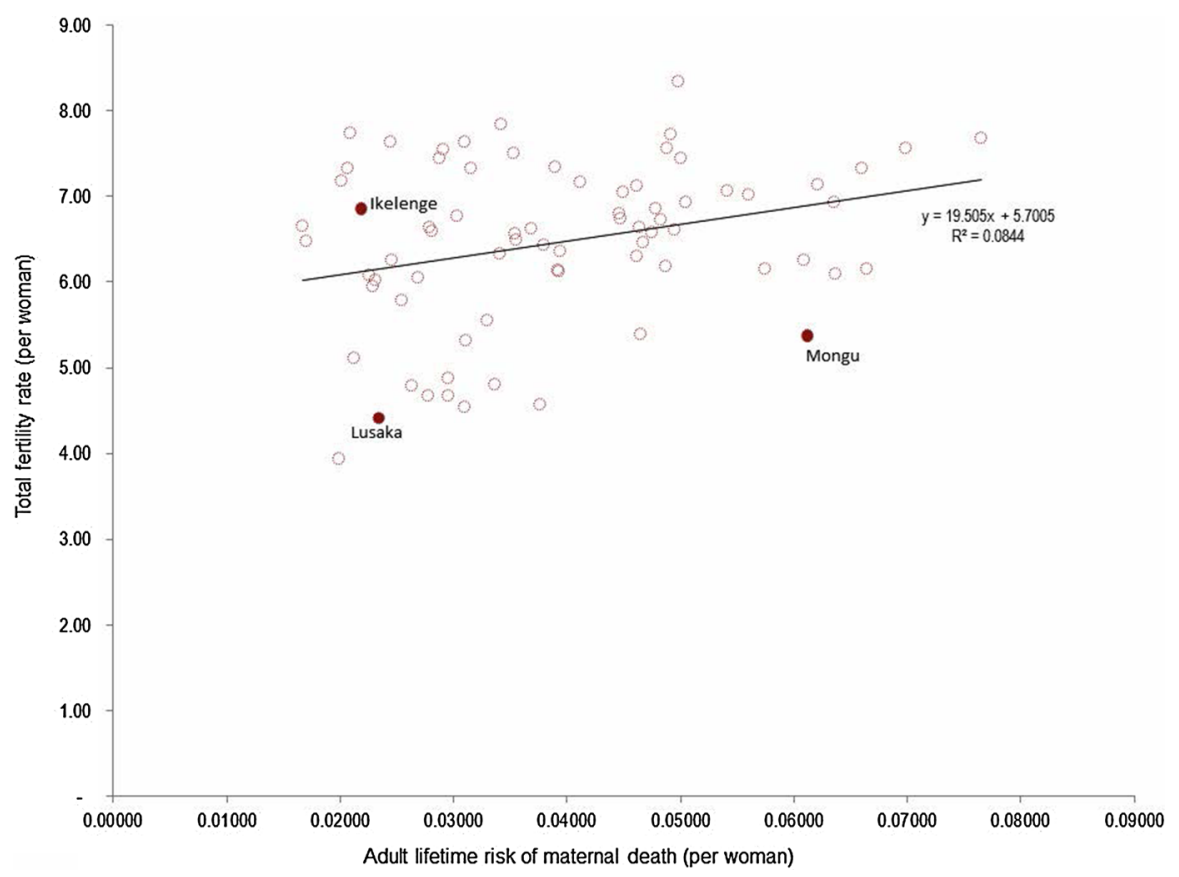

Fig. 2 District level scatterplot of total fertility rate (TFR) and adult lifetime risk (ALTR), Zambia 2010 census

some heterogeneity across districts. For example, women in Ikelenge district had a TFR of 6.86 and an ALTR of $2.2 \%$ compared to women in Lusaka district with a similar level of adult lifetime risk (2.3\%) but lower TFR (4.42) and Mongu district with a TFR of 5.38 (lower than that for Ikelenge district) had an ALTR of $6.1 \%$ (Fig. 2).

Like the TFR, the PMFD was higher for Ikelenge district (18.5\%) compared to $11.3 \%$ for Mongu and $8.3 \%$ for Lusaka districts (Fig. 3), although the district had a lower ALTR.

\section{Discussion}

We found significant geographic differences in the lifetime risk of pregnancyrelated death among females aged 15 across the 74 districts of Zambia at the time of the census in October 2010. Overall, $3.7 \%$ of females aged 15 would die a pregnancy-related death before age 50. At district level, the risk ranged from $1.7 \%$ in the district with lowest risk (Gwembe) to $7.7 \%$ in the district with the highest risk (Chilubi). Our results revealed patterns of clustering of districts with similar levels of pregnancy-related mortality risk. We found clustering of low-risk districts in Lusaka, Muchinga, Copperbelt, North Western and Southern provinces, and clustering of high-risk districts in Western and Luapula provinces. The lifetime risk 


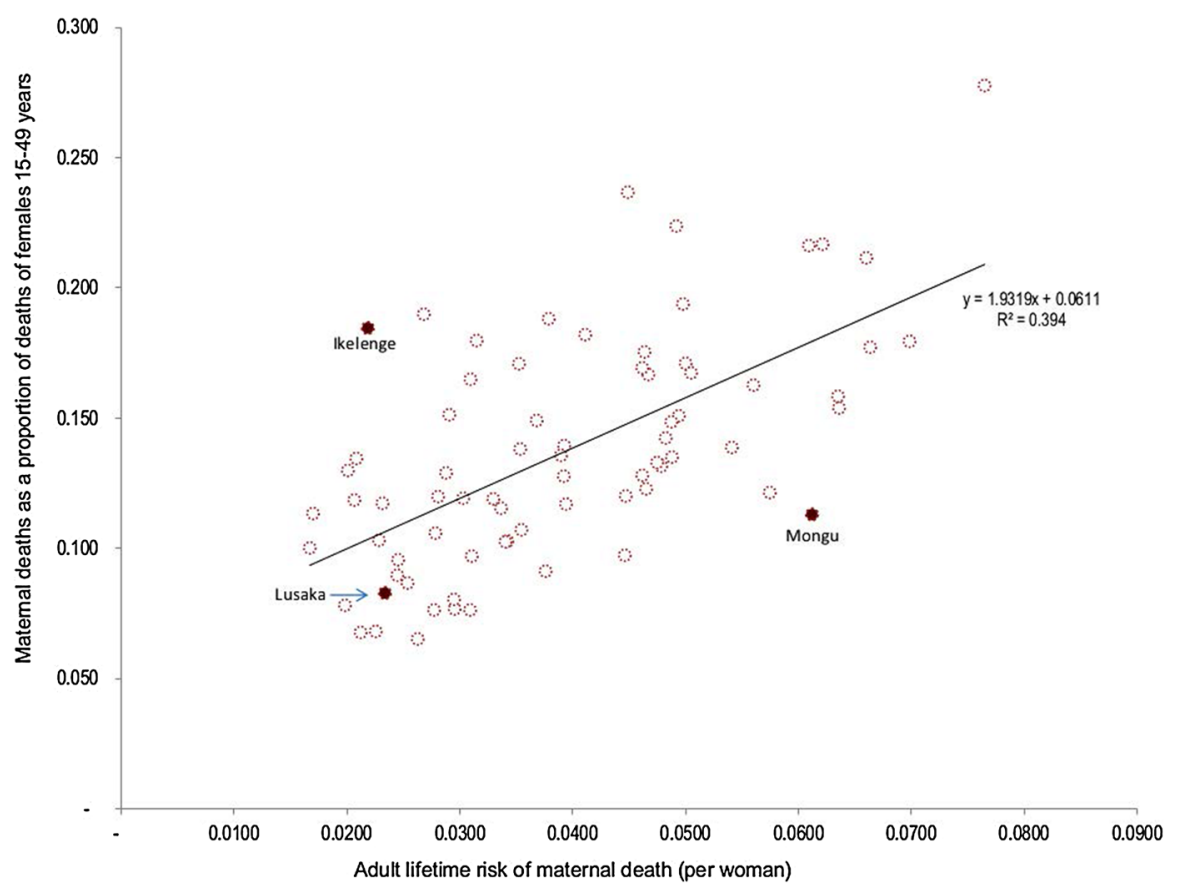

Fig. 3 District-level scatterplot of proportion of female deaths that were pregnancy-related (PMFD) and adult lifetime risk (ALTR), Zambia 2010 census

of pregnancy-related death was weakly positively associated with the district's level of fertility and more strongly positively associated with the proportion of deaths that were pregnancy-related.

The concentration of high-risk districts in Western and Luapula provinces could be partly associated with the level of development and household poverty in the two provinces. Several rounds of the national Living Conditions Monitoring Surveys (LCMS) have consistently shown the two provinces to be the least developed, with the highest levels of poverty among households (Central Statistical Office 2011). The two provinces are also predominantly rural; more than $85 \%$ of the population in Western province and over $80 \%$ in Luapula province reside in rural areas (Central Statistical Office 2012a). There was also clustering of high-risk districts along the borders between the Copperbelt, Central and North-Western provinces (i.e. Lufwanyama, Mpongwe, Kapiri Mposhi and Kasempa districts). About $60 \%$ of districts with ALTR greater than the national average were predominantly rural ( $>85 \%$ of the population residing in rural areas). Access to health services remains a challenge for most rural populations in Zambia. Most rural health centres cannot provide basic emergency obstetric care because they are lacking the required number of appropriately skilled health care workers, supplies and equipment (Gabrysch et al. 2011; Kyei et al. 2012; Levine et al. 2008; Stekelenburg et al. 2004). Women living in rural areas are therefore more exposed to the risk of pregnancy-related death due to relatively poor access to health services. For 
example only $32 \%$ of women in Zambia deliver in health facilities in rural areas compared to $84 \%$ in urban areas (Central Statistical Office et al. 2009).

Although teenage childbearing and marriages are common in most parts of Zambia, the problem is bigger in Western province. Data from three rounds of the Demographic and Health Survey (DHS) conducted between 2001 and 2014 show that $40-44 \%$ of adolescent females aged 15-19 in Western province are already mothers or pregnant with their first child at the time of the survey, which is a higher percentage than in most of the other Zambian provinces (Central Statistical Office et al. 2003, 2009, 2014). In addition, a much earlier study (from 1994 to 1995) in four of the six districts in Western province showed extremely high levels of illegally induced abortions at the time, with an estimated induced abortion mortality ratio of 120 induced abortion-related deaths per hundred thousand live births overall (Koster-Oyekan 1998). Complications of abortion are a major direct cause of maternal morbidity and mortality among adolescent females in Zambia (Castle 1990; Nsemukila et al. 1998). Although the country has had an abortion law since 1972 (Termination of Pregnancy Act 1972), access to abortion services is highly centralised, available mainly in public hospitals and greatly restricted on medical, social or economic grounds and by bureaucratic requirements (e.g. consensus needed from three physicians) (Castle et al. 1990).

The high concentration of low-risk districts in Lusaka province is probably tied to better access to health facilities and services. Overall $78 \%$ of women surveyed in the 2007 DHS in the province delivered in health facilities, assisted by a skilled health provider (Central Statistical Office et al. 2009). The four low-risk districts are in very close proximity to each other and to the capital city Lusaka, and therefore adequately linked by a good road network and transport services. The province also has the highest concentration of health workers (Ferrinho et al. 2011).

The observed geographic diversity and clustering goes beyond the mere spatial distribution of districts, and cannot be explained purely by differences between rural and urban population distributions within districts or provinces. Instead, access to health care services and quality of health care services, which are both linked to the socio-economic development of a region, seems important. This is linked to the three delays theory by Thaddeus and Maine (1994): the risk of pregnancy-related mortality is influenced by the complex interaction of determinants that might culminate in delay in deciding to seek care, delay in reaching a health facility, and delay in receiving quality care. These delays operate at the individual level, the community level, and the health facility level. Next to the role of socio-economic development and health system determinants, cultural determinants are important as well in the decision to seek care, whereas geographic determinants are important as well in the delay in reaching a health facility. These determinants go beyond ruralurban differences.

Whereas high fertility is frequently mentioned as an important determinant of high (risks of) pregnancy-related mortality (Campbell and Graham 2006; Ronsmans et al. 2006; World Health Organisation 2005), our analysis found a positive but rather weak association between the ALTR and TFR across the 74 districts. Actually, high fertility occurred in all districts (all but one district had TFR $>4$ per woman), and in some districts, the association between the ALTR and TFR did not 
conform at all to the expected pattern of high fertility and high risk of pregnancyrelated death. For example the three districts Mbala, Chinsali and Chama were among those with the lowest lifetime risk but also among the districts with very high fertility (TFR $>7$ children per woman). It is worth noting that the level of fertility serves as an indicator of the level of obstetric risk in a population particularly when childbirth starts too early, too many births occur too close to each other and when births occur late in the reproductive years (Campbell and Graham 2006; Ronsmans et al. 2006; World Health Organisation 2005). Thus if more births occur to low-risk women aged 20-34 as opposed to high-risk groups of women aged less than 20 and over 35, the risk could be low despite the high fertility. This might be-at least partly - the case for the above-mentioned districts with high TFR and low ALTR.

The positive association of ALTR with the proportion of pregnancy-related deaths (PMFD) was stronger than that between ALTR and TFR. But, as was the case with the TFR, the PMFD was high in some districts where the lifetime risk of a pregnancy-related death was low. For example Ikelenge district had a higher PMFD (18.5\%) but much lower ALTR compared to Mongu district with a high ALTR but low PMFD (11.3\%). A possible explanation could lie in the level of all-cause mortality prevailing in the two districts. Despite the high proportion of female deaths being pregnancy-related in Ikelenge district, all-cause mortality was lower in Ikelenge district than in Mongu district and could have partly contributed to the lower ALTR, as survival to age 15 and subsequent age groups in the reproductive age group 15-49 was higher for females in Ikelenge district than in Mongu district. The low all-cause mortality in Ikelenge district could be partly a result of the relatively low HIV prevalence in particular rural parts of the North Western province (Central Statistical Office et al. 2003, 2009, 2014). Although the geographical differentials in the prevalence of diseases such as malaria, HIV and PTB could partly explain the observed differentials in the lifetime risk of dying a pregnancy-related death, lack of data on disease burden at district level made it a challenge for us to make any meaningful conclusion or attribution to any such diseases.

Our estimates of lifetime risk of pregnancy-related death are likely to overstate the actual risk of dying a maternal death, since pregnancy-related deaths include both maternal and non-maternal deaths. Therefore, interpretation and use of these estimates must make consideration of that fact. Further, our study used only one data source (2010 census data) to analyse lifetime risk of pregnancy-related deaths at district level and therefore could not accurately attribute the observed levels and patterns to direct determinants of risk such as contraceptive prevalence (Stover and Ross 2010), proportion of facility deliveries or skilled attendance at birth (Campbell and Graham 2006) in each of the districts, among other factors. Reporting bias in both overall deaths and pregnancy-related deaths could also have affected the estimates. Misclassification of pregnancy-related deaths is a likely source of error by households reporting deaths of reproductive-age women (World Health Organisation et al. 2014). Deaths of women in the early stages of pregnancy are less likely to be reported as pregnancy-related deaths, while deaths resulting from complications of abortion might be underreported or omitted due to stigma. A study at Zambia's highest national referral hospital in Lusaka found that $44 \%$ of pregnancy-related 
deaths were due to non-obstetric causes, among them, malaria and tuberculosis (Ahmed et al. 1999). Such deaths would therefore also be misclassified and misreported by households in a census. A challenge in evaluating and adjusting maternal or pregnancy-related deaths reported in censuses is the lack of methods for making such evaluations and adjustments, and this has been noted by several other studies based on census data (Hill et al. 2009, 2010; Stanton et al. 2001). Improvements in reporting by households, as well as development of evaluation and adjustment methods, could lead to more robust estimates in the future. Given the scope of the census, reporting errors are likely to be random rather than systematic across districts. Standard training curriculum and instructions were given to all census enumerators in all districts, and interviews were conducted using the same questionnaires. Some bias could have arisen from the translation of questions from the English questionnaire into the local language of the district, but is likely to be minor since questionnaire translation was part of the standard training curriculum. Age misreporting and misreporting of deaths and births are common in censuses across developing countries, partly due to the high proportion of illiterate people, but even such errors when measured at district level tend to be random, rather than systematic. Therefore any errors are likely to be spread across all districts and not likely to affect district comparisons. Our study thus provides plausible estimates of lifetime risk of pregnancy-related death and its geographical distribution at district level in Zambia.

\section{Conclusions}

Females in Zambia have a high lifetime risk of pregnancy-related death overall but this risk varies greatly across the different districts of the country. The observed diversity is larger than when merely studying differences between provinces and is only weakly linked to differences in fertility levels. The observed clustering of districts around similar lifetime risk levels cannot be explained by rural-urban differences alone. Instead, differences in the level of socio-economic development among districts, especially linked to the delivery of health services, seem important. Access to and quality of health services available (especially maternal health services), both of which are linked to the socio-economic development of a region, are key in reducing the lifetime risk of pregnancy-related death. Geographical studies that go beyond the rural-urban differences and the province level allow the recognition of districts with varying levels of risk. Our analysis has identified seventeen districts where improved access to high-quality maternal health services seems to be particularly urgent.

Acknowledgments This study is part of Ph.D. training at the University of Bergen and is fully supported by the Norwegian State Educational Loan Fund.

Open Access This article is distributed under the terms of the Creative Commons Attribution 4.0 International License (http://creativecommons.org/licenses/by/4.0/), which permits unrestricted use, distribution, and reproduction in any medium, provided you give appropriate credit to the original author(s) and the source, provide a link to the Creative Commons license, and indicate if changes were made. 


\section{Appendix}

See Fig. 4.

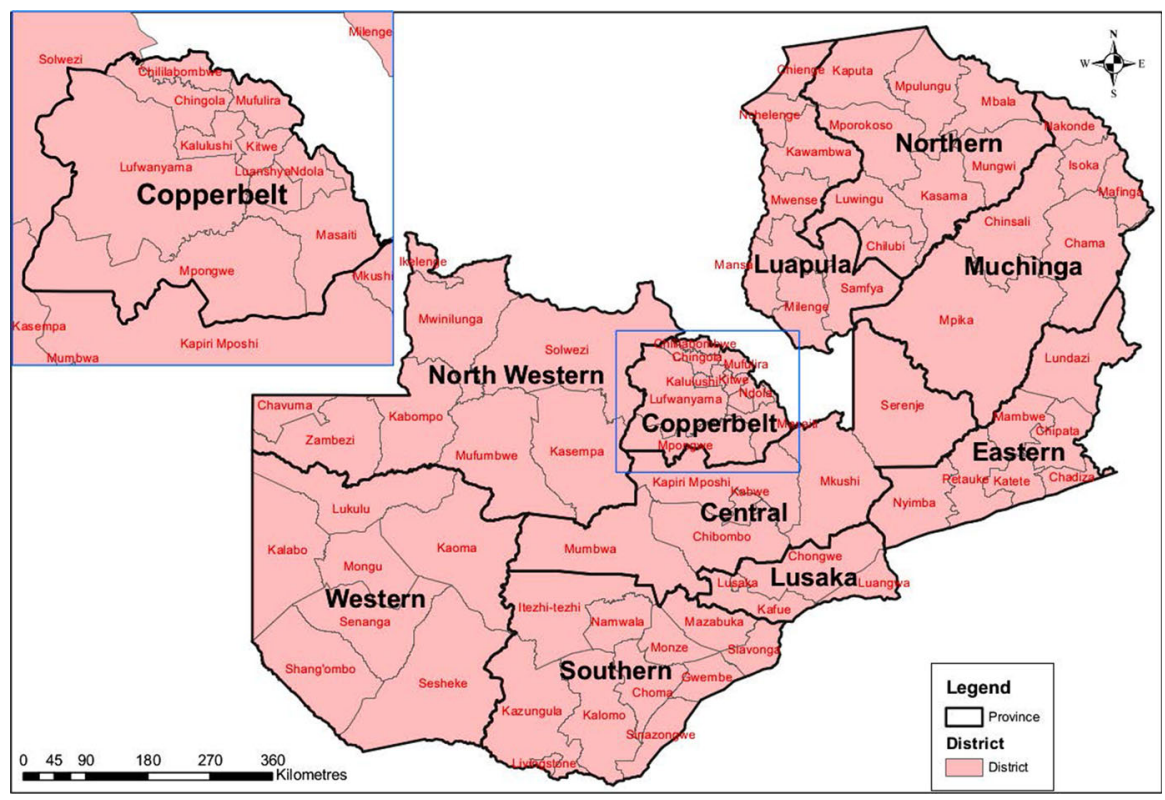

Fig. 4 Map of Zambia showing provincial and district boundaries

\section{References}

Ahmed, Y., Mwaba, P., Chintu, C., Grange, J. M., Ustianowski, A., \& Zumla, A. (1999). A study of maternal mortality at the University Teaching Hospital, Lusaka, Zambia: The emergence of tuberculosis as a major non-obstetric cause of maternal death. The International Journal of Tuberculosis and Lung Disease, 3(8), 6.

Banda, R., Fylkesnes, K., \& Sandøy, I. F. (2015). Rural-urban differentials in pregnancy-related mortality in Zambia: Estimates using data collected in a census. Population Health Metrics, 13(32). doi:10. 1186/s12963-015-0066-9.

Campbell, O., \& Graham, W. J. (2006). Strategies for reducing maternal mortality: Getting on with what works. The Lancet, 368, 1284-1299.

Castle, M. A., Likwa, R., \& Whittaker, M. (1990). Observations on Abortion in Zambia. Studies in Family Planning, 21(4), 5.

Census Bureau, U. S. (1994). Population analysis with microcomputers. Washington, DC: U.S. Census Bureau.

Central Statistical Office. (2011). Living conditions monitoring survey, 2006 \& 2010. Lusaka: Central Statistical Office.

Central Statistical Office. (2012a). Zambia 2010 census of population and housing; population summary report. Lusaka: Central Statistical Office.

Central Statistical Office. (2012b). Zambia 2010 census of population and housing; national descriptive tables (Vol. 11). Lusaka: Central Statistical Office.

Central Statistical Office. (2013). Migration and urbanisation analytical report. Lusaka: Central Statistical Office. 
Central Statistical Office, Central Board of Health, \& ORC Macro International. (2003). Zambia Demographic and Health Survey, 2001-2002. Calverton, MD: Central Statistical Office, Central Board of Health, and ORC Macro International.

Central Statistical Office, Ministry of Health, Tropical Diseases Research Centre, \& ICF Macro International. (2014). Zambia demographic and health survey, 2013-14. Rockville, MD: Central Statistical Office, Ministry of Health, Tropical Diseases Research Centre, and ICF Macro International.

Central Statistical Office, Ministry of Health, Tropical Diseases Research Centre, University of Zambia, \& ORC Macro International. (2009). Zambia demographic and health survey, 2007. Calverton, MD: Central Statistical Office, Ministry of Health, Tropical Diseases Research Centre, University of Zambia, and ORC Macro International.

Environmental Systems Research Institute. (2013). ArcGIS 10.2. Redlands. Carlifornia: ESRI.

Ferrinho, P., Siziya, S., Goma, F., \& Dussault, G. (2011). The human resource for health situation in Zambia: deficit and maldistribution. Human Resources for Health, 9(30). doi:10.1186/1478-4491-9-30.

Gabrysch, S., Simushi, V., \& Campbell, O. M. R. (2011). Availability and distribution of, and geographic access to emergency obstetric care in Zambia. International Journal of Gynecology and Obstetrics, $114,174-179$.

Graham, W., Foster, B. L., Davidson, L., Hauke, E., \& Campbell, M. R. O. (2007). Measuring Progress in reducing maternal mortality. Best Practice and Research Clinical Obstetrics and Gynaecology, 22(2), 425-445.

Hill, K., Queiroz, B. L., Wong, L., Plata, J., Del Popolo, F., Rosales, J., \& Stanton, C. (2009). Estimating pregnancy-related mortality from census data: Experience in Latin America. Bulletin of the World Health Organisation, 87(4), 288-295.

Hill, K., \& Stanton, C. (2011). Measuring maternal mortality through the census: Rapier or bludgeon? Journal of Population Research, 28, 31-47.

Hill, K., Stanton, C., Levin, M., Queiroz, B.L., Choi, Y., Mahanani, A. W. R., \& AbouZahr, C. (2010). Measuring maternal mortality from a census: Guidelines for potential users, 2nd revision, 2009. Geneva: The World Health Organisation.

Hill, K., Stanton, C., Levin, M., Queiroz, B. L., Choi, Y., Mahanani, A. W. R., \& AbouZahr, C. (2011). Measuring maternal mortality from a census: Guidelines for potential users, 3rd revision. Geneva: The World Health Organisation.

Koster-Oyekan, W. (1998). Why resort to illegal abortion in Zambia? Findings of a community-based study in Western Province. Social Science and Medicine, 46(10), 1303-1312.

Kyei, N. A., Chansa, C., \& Gabrysch, S. (2012). Quality of antenatal care in Zambia: A national assessment. BMC Pregnancy and Childbirth, 12, 151.

Le Bacq, F., \& Rietsema, A. (1997). High maternal mortality levels and additional risk from poor accessibility in two districts of northern province, Zambia. International Journal of Epidemiology, 26(2), 357-363.

Levine, A. C., Marsh, R. H., Nelson, S. W., Viola-Tyler, L., \& Burke, T. F. (2008). Measuring access to emergency obstetric care in rural Zambia. International Journal of Emergency Medicine, 1, $113-119$.

Nsemukila, B. G., Phiri, D. S., Diallo, H. M., Banda, S. K., Benaya, W. K., \& Kitahara, N. (1998). A study of factors associated with maternal mortality in Zambia. Lusaka: Ministry of Health and UNFPA.

Ronsmans, C., Graham, W. J., \& on behalf of The Lancet Maternal Survival Series Steering Group. (2006). Maternal mortality: Who, when, where, and why. The Lancet, 368, 1189-1200.

Say, L., Chou, D., Gemmill, A., Tunçalp, Ö., Moller, A. B., Daniel, J., et al. (2014). Global causes of maternal death: A WHO systematic analysis. The Lancet, 2, e323-e333.

Shryock, H. S., \& Siegel, J. S. (2004). The methods and materials of demography (2nd ed.). London: U.S. Bureau of the Census.

Stanton, C., Hobcraft, J., Hill, K., Kodjogbe, N., Mapeta, W. T., Munene, F., et al. (2001). Every death counts: Measurement of maternal mortality via a census. Bulletin of the World Health Organisation, 79(7), 657-664.

Stekelenburg, J., Kyanamina, S., Mukelabai, M., Wolffers, I., \& van Roosmalen, J. (2004). Waiting too long: low use of maternal health services in Kalabo, Zambia. Tropical Medicine and International Health, 9(3), 390-398.

Stover, J., \& Ross, J. (2010). How increased contraceptive use has reduced maternal mortality. Maternal and Child Health Journal, 14, 687-695. 
Termination of Pregnancy Act Chapter 304 of the Laws of Zambia. (1972). Lusaka: Government of the Republic of Zambia.

Thaddeus, S., \& Maine, D. (1994). Too far to walk: maternal mortality in context. Social Science and Medicine, 18(8), 1091-1110.

United Nations. (1983). Manual X: Indirect techniques for demographic estimation. New York: United Nations.

United Nations Statistics Division. (2008). Principals and recommendations for population and housing censuses, revision 2. New York: United Nations.

Vork, F. C., Kyanamina, S., \& van Roosmalen, J. (1997). Maternal mortality in rural Zambia. Acta Obstetrica Gynecolica Scandinavica, 76(7), 646-650.

Wilmoth, J. (2009). The lifetime risk of maternal mortality: Concept and measurement. Bulletin of the World Health Organisation, 87(4), 256-262.

World Health Organisation. (2005). The world health report, 2005: Making every mother and child count. Geneva: World Health Organisation.

World Health Organisation, United Nations Children's Emergency Fund, United Nations Population Fund, \& The World Bank. (2012). Trends in Maternal Mortality: 1990 to 2010. Geneva: World Health Organisation.

World Health Organisation, United Nations Children's Fund, United Nations Population Fund, The World Bank, \& The United Nations Population Division. (2014). Trends in maternal mortality: 1990 to 2013. Geneva: World Health Organisation.

World Health Organization. (2009). International statistical classification of diseases and related heath problems, 10th revision (2008th ed.). Geneva: World Health Organisation. 